\title{
Assessing the Impact of Computer Mediated Communication (CMC) on Productivity and Efficiency in Faecal Sludge Management: A Case Study of the Giant Faecal Sludge Management Company in Ghana
}

\author{
Florence Asiamah'1, Issahaku Ahmed1 ${ }^{*}$ Esi Awuah², Florence Cobbold1, Lola Asiseh Ashitey1 \\ ${ }^{1}$ Sewerage Systems Ghana Ltd., Accra, Ghana \\ ${ }^{2}$ Department of Civil Engineering, Kwame Nkrumah University of Science and Technology, Kumasi, Ghana \\ Email: florasiamah@gmail.com, *eagleskertoozer@yahoo.co.uk, esiawuahrt@gmail.com, fcobbold@hotmail.com, \\ afilola@yahoo.co.uk
}

How to cite this paper: Asiamah, F., Ahmed, I., Awuah, E., Cobbold, F. and Ashitey, L.A. (2018) Assessing the Impact of Computer Mediated Communication (CMC) on Productivity and Efficiency in Faecal Sludge Management: A Case Study of the Giant Faecal Sludge Management Company in Ghana. Journal of Human Resource and Sustainability Studies, 6, 235-248.

https://doi.org/10.4236/jhrss.2018.64040

Received: August 8, 2018

Accepted: November 17, 2018

Published: November 20, 2018

Copyright $\odot 2018$ by authors and Scientific Research Publishing Inc. This work is licensed under the Creative Commons Attribution International License (CC BY 4.0).

http://creativecommons.org/licenses/by/4.0/ (c) (i) Open Access

\begin{abstract}
Today's environment had seen technology taking the center stage in research, and several researches in this area assess the impact of technology on the society and business organizations. This study outlines the impact of computer mediated communication (CMC) on productivity and efficiency in the faecal sludge industry and Sewerage Systems Ghana Limited was used as a case study. Selective sampling technique was used to identify the institution and respondents were randomly selected to undertake the study. A total of 92 respondents were engaged and a questionnaire was administered in order to get the required responds. The study indicates that about $53 \%$ of the respondents admitted to the use of emails as medium in communication to be the best medium in attaining high efficiency and productivity, while $28 \%$ believed the use of What's App application would improve the effectiveness and productivity. Some respondents preferred other methods, for example, communicating face to face which they have highlighted is a medium which enhances interpersonal relationships. The use of printed memo and letters as well as the use of the notice boards was also endorsed to have positive consequence on productivity and efficiency. It was noted that the usage of CMC is highly dependent on age and educational background. As the age of the respondents increased, there was decrease in the utility acceptance of CMC and the reverse was noted for educational background. The highly rated and preferred medium of communication based on the study is the most used medium utilized by Sewerage Systems Ghana Ltd. Employing the most preferred
\end{abstract}


medium for communication in the organization is evidenced in the high performance of the staff which is reflective in the overall performance of the plant operations. The application of the CMC and the utilization of the appropriate medium or media in the management of faecal sludge highly aided the productivity and efficiency of personnel as well the overall performance of the plant operations and hence the organization.

\section{Keywords}

Computer Mediated Communication, Faecal Sludge Management, Productivity, Efficiency, SSGL

\section{Introduction/Literature Review}

Today's world is characterized with technology and every society is adopting to its use to either facilitate business or social networks. This has become an important asset or tool for human beings in all walks of life [1]. As Green [2] puts it, technology has proven to be an all important tool for humans which plays a major role since the beginning of human race from the faces of life, such as the use of fire as a weapon and a tool for development, through invention of light bulb that gives birth to the electrification age and the development of computers and internet which describes our current age of life. Rogers [3] makes an assertion that microcomputer is among the most important innovations of our present age if we should assess its significance and impact in schools, homes, businesses and social centers. Again, according to Rogers [4], the internet was a medium that exposed the computer to be a global craze. In 2002, about 544 million people were estimated to use the internet internationally which has kept on increasing [2].

According to the history records, William Oughtred in 1622 invented the first computer described as the abacus. However, the first computer resembling today's modern machines which was described back then as the Analytical Engine was conceived or birthed by a British mathematician known as Charles Babbage between 1833 and 1971. For today's business environment, computers and internet are very important or cannot do without asset. It is the medium with which members in a business environment whether close or worlds apart use to communicate very important information. Computers have wide range of networks, which connects every individual through their working machines whether in same location or within the work environment or outside the working environment. These linkages are made possible by the internet, which has many advantages. Some of these advantages include facilitating archive of information which could be shared and communicated with others, helping in prevention of barriers in communications due to distance, saving time where people would have to travel long distances to deliver simple messages and information and many more. The world is now described as a global world because of the ease of 
share of information and access of information and it is very paramount through emails or electronic mails by a hit of a button to either a group of people within and outside of the working environment at the side time while they could share this information individually. Now big companies are making use of this medium of communication to sell their products and advertise their product to gain wider clientele base and small to medium companies are doing same through this same medium. Until the beginning of the computer era in 1946 which is also known as the interactive communicative era, research has indicated that there were three different era of communication [3], but they were rather cumbersome, less efficient and time consuming. New technology has been adopted by individuals as well as organizations with the existence of the internet. This has had different impact on almost every aspect of the human life. According to Rogers [4], the internet was developed in the year 1969 when ARPANET network was initiated to allow thirty US Department of Defense contractors to share computer software and databases. He recounts that the email system became the main function for network users after the computer software and database system. These two systems were merged in 1980 which gradually gained grounds within 18 years and the rate at which it was accepted has made a huge impact in today's world. In addition, Kiesler, Siegel, \& McGuire [5] states that Computer Mediated communication has the advantage of affecting workplace interactions where, members within a group participated more in sharing of ideas and gave room for members at all backgrounds to contribute where high status members did not dominate the interaction to the same degree of face to face meetings. This is believed to have happened because Computer Mediated communication has the ability to sieve out certain personal and social behavioral cues; for example, body language and voice tone which are used in the direct contact interactions.

Irrespective of all these advantages, there are some associated disadvantages which may include, distort of communication and others. With Computer Mediated communication the richness of a communication is believed to be lost because having that physical contact would give both the sender and the receiver of any information a clear meaning [6]. Although Computer Mediated communication is believed to take away the richness in conversations such as focus, different ways to convey messages as well as certain cues and clues, it is believed that in Computer Mediated communication, a sure way of interpreting and communicating information based on some factors such as sender or recipient role in the organization [7], thread of conversations, type of relationship that exists between sender and recipient, subject of message and more.

According to Roger [3], research has shown that Computer Mediated Communication had a positive impact with the flow of information across all levels within an organization. Kiesler, Siegel \& McGuire [5] also has it that, Computer Mediated Communication aided in organizational authority and power, helped in decision making and other creative processes. Rice \& Blair [8] also has it that Computer Mediated communication has also been credited with recognizable 
improvement in employee task efficiency, planning flexible work schedule, eliminating manual action plans, responding to the environment, time management, action plans, composing and preparing written documents. Computer Mediated communication goes beyond all other forms of communication which is aided by the use of computer and it is known to improve information processing systems in organizations.

Like other businesses and sectors [9] [10], Computer Mediated Communication (CMC) is seen to be a very important parameter in the Faecal Sludge Management (FSM) sector of operations and it has the potential to affect productivity and efficiency. Research has indicated that, sewage and faecal sludge treatment plants may gradually increase in Ghana and a large demand for information on appropriate procedures and technologies has to be developed [11]. There are several prospects in the management of faecal sludge in Ghana [11] [12] [13] [14] [15] and this is also evidenced with the progress observed in recent times with regard to establishment of a sanitation ministry. With the attention being given in the area of sanitation which encompasses the treatment of faecal sludge and sewage in attaining the sustainable development goals, it has become imperative for detail research to be conducted across all facet of its management. This study therefore, seeks to identify some important values of Computer Mediated Communication on productivity and efficiency of employees in the FSM sector. Also, assess whether Computer Mediated communication has the potential to increase a worker's efficiency and productivity as well as identify any disadvantages of the use of Computer Mediated communication and interpersonal interactions of individuals by the use of Computer Mediated Communication in FSM. This assessment of Computer Mediated Communication on productivity and efficiency in FSM was carried out using SSGL as a case study. This is because in Ghana, SSGL is a giant leader in the management of liquid waste. Just like the other sectors of businesses who had adopted the use of Computer Mediated Communication to enhance or gain competitive advantage over their competitors [9] [10], so is this work would want to figure out the consequence of the application of CMC in liquid waste management. The knowledge of this study would highlight whether Computer Mediated Communication will cause the same effect on staff in terms of efficiency and productivity as it is in the other sectors of businesses.

The objective of this study was attainable through asking questions such as: Does Computer Mediated Communication such as email and what's app improve productivity and efficiency of the organization or in FSM? It is anticipated that feedback and result of the study would pave the way for managers and organizations operating in the management of liquid waste (Sewage and Faecal Sludge) to enact the implementation of CMC in their operations. And this is however, expected to ensure the workers in FSM are highly efficient and productive. There may be a bit of a barrier in face to face interaction and that some factors such as age, gender, and educational level will affect the use of Computer Mediated communication. 


\section{Methodology}

\subsection{Setting and Context}

This paper made its assessment in the Faecal Sludge Management setting in Ghana. Sewerage Systems Ghana Limited (SSGL) is a privately owned institution set to give Ghanaians a more decent and environmentally acceptable standard facility for liquid waste management. It is a Public Private Partnership arrangement with the Local Government and Rural Development to predicate an international best practice where faecal and sewerage systems are usually owned and operated by municipal authority. SSGL has a total of 128 employees which comprises of 41 staff belonging to the executive, managers, administrative and professional staff [12] who have access to a networked computer and what's up platform. The 41 personnel represent $32 \%$ of the total workforce with 87 staff (68\%) being operational staff. SSGL since its inception saw the need to provide most of its staff with a networked computer to aid in the work they do as business evolution era has made it imperative. The idea was to ensure staff use this medium to uplift effectiveness and high productivity. However, although SSGL is doing well in terms of handing over information from person to person or among various department, this paper seeks to identify if the employees share the same thought of being effective and productive with the Computer Mediated communication that has been provided. Would they have been better off without the Computer Mediated communication platforms, whether they would have just been better off with the "Hand me down" old system or manual way of transferring information among personnel.

\subsection{Sampling and Data Collection}

In this study, selective sampling was used to select SSGL for the case study because SSGL is a giant leader with little or no competition at all when it comes to FSM in Ghana. The random sampling technique was used to determine the sample size from the population of employees. The objectives of this study guided us in the choice of questions to be adopted for the study. The type of questions that were asked was very clear and self-explanatory with a well-defined response options. To be able to get accurate information, staff were randomly selected for this survey. Those selected for the survey cuts across all levels in the organizational structure. However, as a tradition in research, there are some occurrences which cannot be avoided as far as research and collecting of data is concerned. Not everybody was willing to cooperate, some were too busy to complete the questionnaire, and others would just not be interested. Thus, at the end of the survey, 100 questionnaires were sent out but 92 questionnaires were accurately filled for the study which makes our sample size 92. The questionnaire was divided into 3 main parts.

Part A comprised of demographic questions focusing on the age, gender, educational background and level in the organization; that is whether they belonged to the executive group, management or officers or operational group. 
These parameters were chosen because we believed that there would be varied views about the use of Computer Mediated communication based on the parameters mentioned.

Part B of the questionnaire comprised of questions related to the use of emails and what's App platforms and the reason why they would prefer to use these platforms and their rationale behind the importance of using these platforms in relation to executing their tasks and duties at the work environment. This to some extent assesses the advantages and disadvantages of the use of the Computer Mediated communication. It focused on finding how CMC has affected employee relationship in the organization, how CMC has affected their duties to make them productive and efficient in what they do, whether they appreciate the use of Computer Mediated communication to the traditional way of passing down information or the face to face method and their opinion on the method they preferred.

Part $\mathrm{C}$ was also designed to examine the type of gadget they preferred to use in order to make them productive and efficient at the work place. They were also given an opportunity to give their personal opinions on their position with the use of Computer Mediated communication compared to not using it.

\section{Results and Discussions}

The questionnaire designed for this study was distributed randomly to $100 \mathrm{em}$ ployees in SSGL taking into account ages, gender and educational level. Respondents for the questionnaire were a total of 92 comprising 80 men (87\%) and 12 women $(13 \%)$. The margin of percentage of male to female respondents was wide. This is a clear indication that Sewerage Systems Ghana Limited is a male dominated organization. However, it is not surprising due to the area of operation. Data for the study was analyzed based on the three stated objectives. The first objective dealt with the effect Computer Mediated communication has on worker productivity and efficiency in FSM (SSGL).

From Figure 1, about 53\% of respondents indicated the use of emails make them productive and efficient. $28 \%$ indicated what's app made them productive and efficient. $12 \%$ of respondents preferred face to face communication medium, $5 \%$ preferred printed letters and memos and then $2 \%$ of the respondents preferred the notice board to access information.

The second objective for this study was to find out if respondents' age had an impact on the medium they preferred to use to communicate in order to be efficient and productive with their respective duties they carry out. The first objective aided in the finding of the second object which the breakdown is indicated in the table above. It was revealed that out of the $53 \%$ of the respondents who believe the use of emails makes them efficient and productive; $4 \%$ of these respondents were between the ages of 18 - 25 years (Figure 2), 49\% between the ages of 26 - 35 years, $31 \%$ were between the ages of 36 - 45 years and $16 \%$ were in the age range of 46 - 55 years. 
60

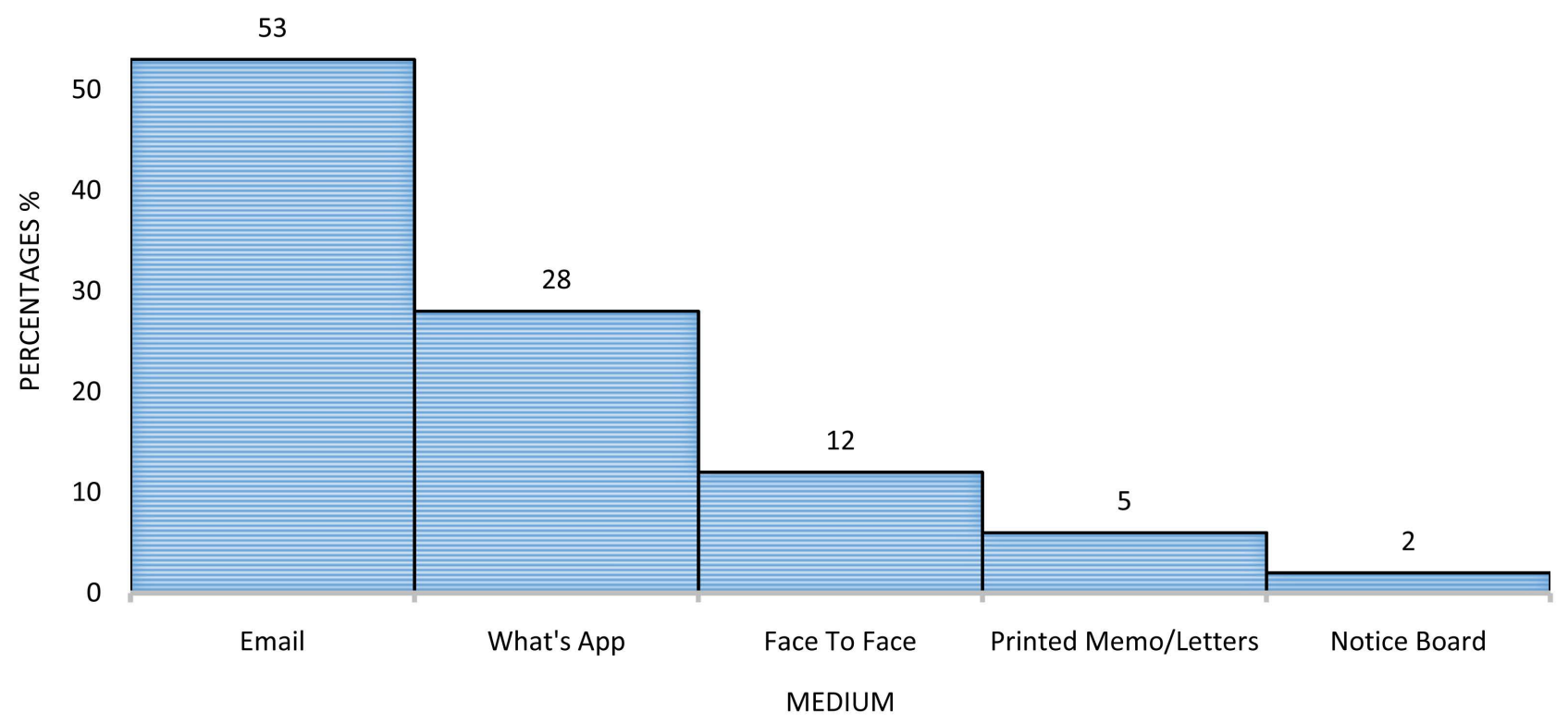

Figure 1. Respondents preferred medium of communication with respect to them being efficient and productive.

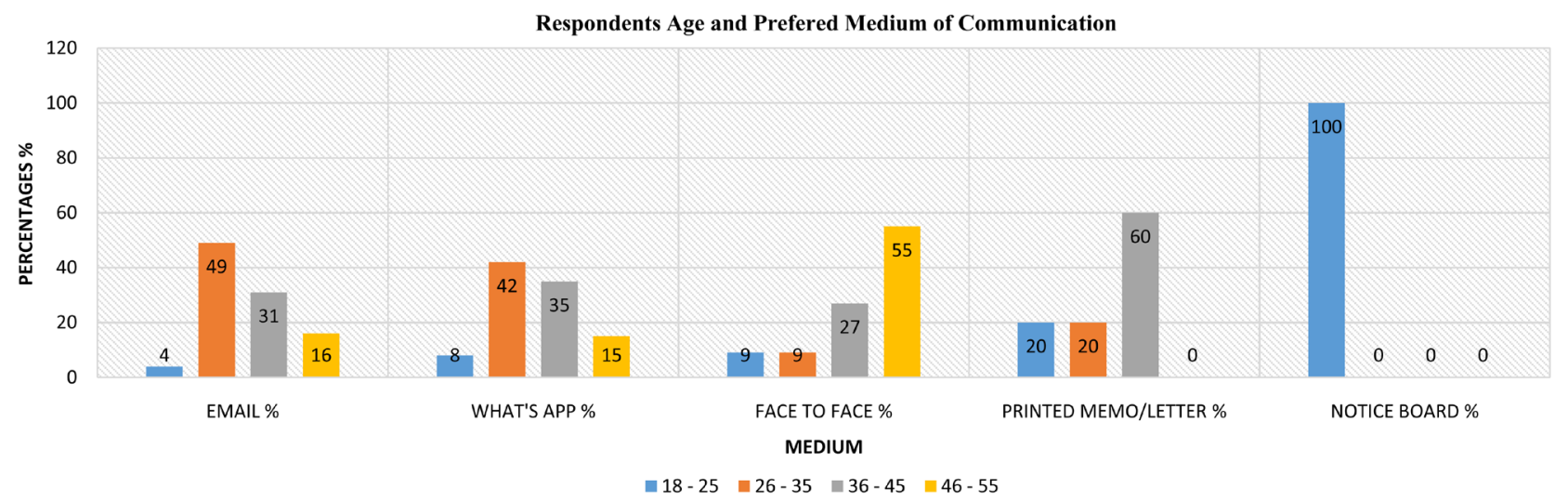

Figure 2. Breakdown of respondent's age and their preferred medium of communication.

Out of the $28 \%$ (Figure 1 ) of the respondents who believes What's App increases productivity and efficiency significantly as a medium of communication; about $8 \%$ of which are between the ages of 18 - 25 years (Figure 2), 42\% were between the ages of 26 - 35 years, 35\%in the range of 36 - 45 years and 15\% 46 55 years. To them, emails and What's App gives them access to information wherever they are, they preferred the two media of communication because it shows evidence of work done, they get access to their data no matter their location, it saved them time to travel or move to other people to give or receive information, they are able to reach a large number of people without having to move to each and every one to deliver information. $12 \%$ of the respondents, of which $9 \%$ were in the age range of 18 - 25 years, another $9 \%$ falling within 26 35 years range, $27 \%$ were in the ages of 36 - 45 years and $55 \%$ were between the 
ages of 46 - 55 years, indicated that they preferred face-to-face medium of communication because it enhances relationships and improves positive organizational culture. To them, since employees spend most of their time in the office it is only appropriate for them to interact with each other to prevent depression or isolation. They believe it is only appropriate that they maintain relationships by interacting physically. In addition, from Figure 2, 5\% of the respondents preferred printed letters and memos to electronic transfer of information or medium of communication. $2 \%$ respondents which consisted of only respondents between the ages of 18 - 25 years on the other hand indicated they preferred information communication through the notice board.

A survey conducted on "The impact of Computer Mediated Communication (CMC) on Productivity and Efficiency in Organization: A Case study of an Electrical Company in Trinidad and Tobago" [9], gave results not so different from what this study generated from the survey. Kenrick \& Prahalad, 2014 had a sample size relatively small compared to this study but the trend of response is almost the same. The results indicated that $73 \%$ agree to the use of Computer $\mathrm{Me}$ diated communication making them productive and efficient whiles $27 \%$ disagree with the use of Computer Mediated communication making them efficient and productive. In this study, a total of about $81 \%$ agrees whiles $19 \%$ disagrees with the assertion. The trend is consistent with the earlier research conducted [9]. Respondents gave reasons for agreeing and disagreeing. For those who agree that Computer Mediated Communication makes them efficient and productive, some of the reasons included the fact that they were able to get information through to a large number of people through a hit of a button, they get instant feedback, emails gave evident of work done and others. It was however stated some reasons for the staff not appreciating emails which they added the following: that E-mails are most often than not taken for granted, that access is not quick enough which sometimes delays urgent matters, that there is excess of information, distraction to interpersonal relationship amongst others. It was established that all the respondents irrespective of these challenges were all using email and it is consistent with the works of Bob and Prahalad [9].

Even though, $53 \%$ opted for only email whiles $28 \%$ opted for only What's App from Figure 1, there were some number of personnel who supported both email and What's App utility. In this regard, about 50\% of respondents believe What's App is very quick and instant as employees carry their phones with them almost everywhere they went. This gives them access to information and response to information. It was noted in this study that almost half of the employees who were in support of emails made them efficient and productive were in also support of the What's App as well. Information on this study with reference to the use of What's App was not reported in earlier works conducted in CMC. Upon further investigation by word of mouth, respondents established that, they had both the emails and the what's app on their phones but the what's app seems to be easily accessible to them as they use it almost every time and sometimes when 
a mail is sent and a follow up message is sent through What's App, they are able to revert and quickly get to their mails to answer or access which ever information is in their mail that needs their attention. However, a noticeable trend from the general comments column suggested that, really it is not a matter or existence of a Computer Mediated Communication that makes employees efficient and productive. Rather it is an aid to them being efficient and productive. This indicates that Computer Mediated Communication in itself does not make employees efficient and productive but a medium that helps them to be efficient and productive in terms of time to convey information and respond to information to take the needed actions.

The third objective was to know which gadget employees/respondents preferred to communicate information through. Majority (34\%) of the respondents opted for laptops (Table 1) of which 3\% were between the ages of 18 - 25 years (Figure 3), 32\% were between the ages of 26 - 25 years, $41 \%$ were between the ages of 36 - 45 years and $24 \%$ were between the ages of 46 - 55 years. For mobile phones, $31 \%$ (Table 1) of personnel preferred such gadget of which $3 \%$ were between the ages of 18 - 25 years, 52\% were between the ages of 26 - 35 years, $35 \%$ were between the ages of 36 - 45 years and 10\% were between the ages of 46 - 55 years. Again, for IPad/tablet $19 \%$ of the respondents were established to prefer the use of this gadget to communicate.5\% was between the ages of $18-25$ years, $42 \%$ were between the ages of 26 - 35 years, 32\% were between the ages of 36 - 45 years and $21 \%$ were between the ages of 46 - 55 years (Figure 3). Very few employees preferred desktops which were about 11\% (Table 1) of which $30 \%$ were between the ages of 36 - 45 years and $70 \%$ were between the ages of $46-55$

Table 1. Summary of collected data and statistical analysis.

\begin{tabular}{|c|c|c|c|c|c|c|c|c|c|c|}
\hline \multirow[b]{2}{*}{ Medium } & \multirow[b]{2}{*}{ Total Score } & \multirow[b]{2}{*}{ Percentages } & \multicolumn{2}{|c|}{$18-25 \mathrm{yrs}$} & \multicolumn{2}{|c|}{$26-35 y r s$} & \multicolumn{2}{|c|}{$36-45 \mathrm{yrs}$} & \multicolumn{2}{|c|}{$46-55$ yrs } \\
\hline & & & $\begin{array}{l}\text { Range } \\
\text { Score }\end{array}$ & Percentages & $\begin{array}{l}\text { Range } \\
\text { Score }\end{array}$ & Percentages & $\begin{array}{c}\text { Range } \\
\text { Score }\end{array}$ & Percentages & $\begin{array}{c}\text { Range } \\
\text { Score }\end{array}$ & Percentages \\
\hline Email & 49 & 53 & 2 & 4 & 24 & 49 & 15 & 31 & 8 & 16 \\
\hline What's App & 26 & 28 & 2 & 8 & 11 & 42.3 & 9 & 35 & 4 & 15 \\
\hline Face to Face & 11 & 12 & 1 & 9 & 1 & 9 & 3 & 27 & 6 & 55 \\
\hline Printed & 5 & 5 & 1 & 20 & 1 & 20 & 3 & 60 & 0 & 0 \\
\hline Notice Board & 2 & 2 & 2 & 100 & 0 & 0 & 0 & 0 & 0 & 0 \\
\hline \multirow[b]{2}{*}{ Gadget } & \multirow[b]{2}{*}{ Total Score } & \multirow[b]{2}{*}{ Percentages } & \multicolumn{2}{|c|}{$18-25$ yrs } & \multicolumn{2}{|c|}{$26-35 \mathrm{yrs}$} & \multicolumn{2}{|c|}{$36-45$ yrs } & \multicolumn{2}{|c|}{$46-55$ yrs } \\
\hline & & & $\begin{array}{l}\text { Range } \\
\text { Score }\end{array}$ & Percentages & $\begin{array}{l}\text { Range } \\
\text { Score }\end{array}$ & Percentages & $\begin{array}{l}\text { Range } \\
\text { Score }\end{array}$ & Percentages & $\begin{array}{l}\text { Range } \\
\text { Score }\end{array}$ & Percentages \\
\hline Mobile Phone & 29 & 31 & 1 & 3 & 15 & 52 & 10 & 35 & 3 & 10 \\
\hline IPAD/Tablet & 19 & 21 & 1 & 5 & 8 & 42 & 6 & 32 & 4 & 21 \\
\hline Laptop & 34 & 37 & 1 & 3 & 11 & 32 & 14 & 41 & 8 & 24 \\
\hline Desktop & 10 & 11 & 0 & 0 & 0 & 0 & 3 & 30 & 7 & 70 \\
\hline
\end{tabular}




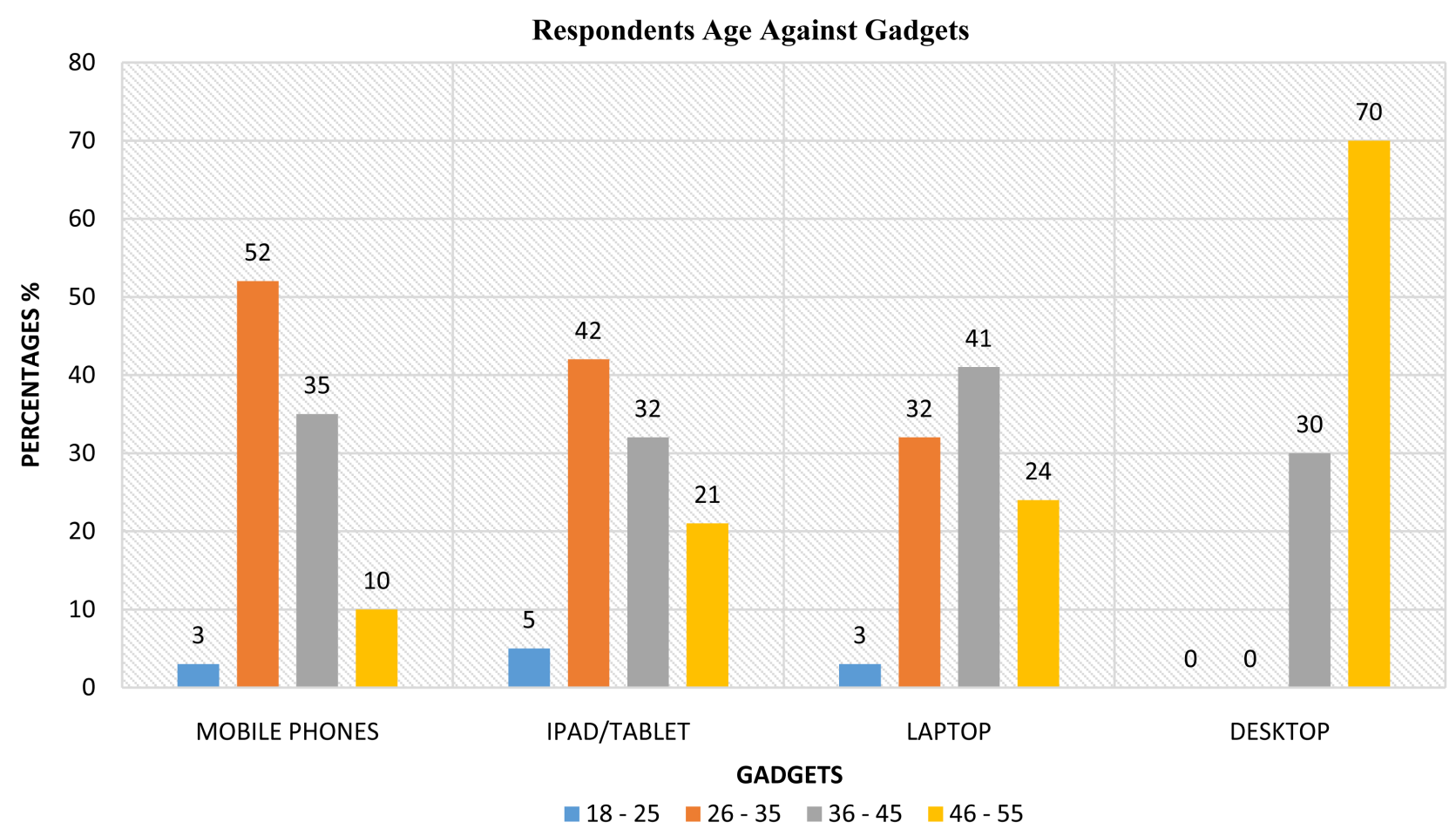

Figure 3. Employee responds of age against their preferred gadget as medium of communication.

years and it could be traced to the fact that they were mostly stationed at the office to be able to execute their work. This is not to say they weren't comfortable with other gadgets. Almost all of them had at least a mobile phone in addition to the desktop which aided them to receive and send information as and when they were not available or stationed at their offices.

In general, the demographical effect from the survey reflected that, employees in the 46 - 55 years' bracket, with educational background of a minimum of Diploma, were in support of the face-to-face and printed memos or letters medium of communication although they use the Computer Mediated Communication to aid them in executing their duties. The works of Bob \& Prahalad [9], identified that, "Workers" usage of CMC was dependent on age, gender and education background. The findings revealed that, as the age of the respondents increased from 26 years to 55 years, there was a decrease in the usage of CMC from $33 \%$ to $20 \%$ ", this was noted to be consistent with this study. However, a majority of the employees between the age ranging from 26 - 35 years with an educational background of a minimum of a diploma in this study, preferred laptops, iPad, tablets and mobile phones to be effective and productive at what they do. Trend of the response indicated that, this category of employees does not see any issue or correlation between Computer Mediated Communication and face to face medium of communication or how it affects relationships. They are well accustomed with technology and believe it is the sure way to go. It was also realized that about $2 \%$ of employees within the age range of $18-25$ years and a minimum educational background of JHS confirmed that emails make 
them less effective and productive and opted for the notice board. Once again, an off the questionnaire enquiry gave reasons of the fact that, they are mostly not connected to the internet and also the Computer Mediated Communications seems a bit cumbersome. This is not to say they do not use any gadget or are not privy to what's app and emails. They are, but they thought seeing a notice on the notice board draws their attention faster than using the other means of communication.

The first objective of this study which was to identify the medium with which employees or respondents preferred to make them efficient and productive at the work place as highlighted in Figure 1; 53\% of the respondents preferred emails, $28 \%$ preferred what's app. $12 \%$ preferred face to face, $5 \%$ preferred printed memos and letters while $2 \%$ preferred the notice board. Objective number two was also to find out how age would influence the choice of medium for communication of employees to make them efficient and productive. Figure 2 clearly specified the age ranges and their preferred medium of communication. The third objective dealt with the gadget respondents preferred use and whether the age factor would be an influence in the choice of gadget and that was been established as well.

\section{Overview}

Figure 1 highlights the respondents preferred medium of communication for efficiency and productivity. This revealed that, the lowest percentage of people $2 \%$ opted for the notice board. $6 \%$ opted for the printed memo and letters which was the second least percentage of the respondents. $12 \%$ were for the face to face. There was however an increase in the percentage of respondents who preferred What's App which recorded 28\% and the maximum of respondents opted for emails with a percentage of $53 \%$. For the $53 \%$ of respondents who preferred emails to be their choice of communication, the highest groups were those in the age range of 26 - 35 years with $31 \%$ score. The choice of emails as medium of choice decreases as the age group of respondents gets older, a statement consistent with the works of Bob and Prahalab [9]. It could be assumed that, people find the importance of interacting with people more when they age than in their youthful stage where they think technology could do and replace all things.18\% of the respondents in the age range of $36-45$ years also chose emails. Only $8 \%$ of the respondents in the age range of 46 - 55 years preferred emails which is a clear indication of the assumption.

Figure 2 also gives us the in-depth information about the preferred medium of communication and the age range and groups who prefer which medium to what. It was also established that the highest group of employees within the age range of 26 - 35 years recording about $31 \%$ preferred emails, $12 \%$ preferred what's app and $1 \%$ for both face to face and printed memos and letters while none opted for the notice board. Respondents within the age range of $36-45$ years also had quite a number of them opting for emails and what's app with $3 \%$ 
for the face to face medium of communication. From Table 1, only $8 \%$ within the range of 46 - 55 years opted for emails and $4 \%$ for what's app although a significant number of them $6 \%$ opted for face to face medium which is a significant improvement from the range of 26 - 35 years and 36 - 45 years respectively. This brought about the assumption that as people grow they tend to opt for face to face rather than emails and other mediums which do not require any contact probably because of the fact that they wish to connect more with others.

Lastly, Figure 3 gives us a fair idea as to which age range or group preferred which gadget to send and receive information. About $14 \%$ of the respondents in the age range of 18 - 25 years preferred mobile phones to the other mediums followed by the range of 36 - 45 years which is $11 \%$. Only $3 \%$ opted for mobile phones in the age range of 46 - 55 years. This makes us understand that, respondents within the age range of 26-35 years are more comfortable with mobile phones. Ipads and tablets also gave the same trend with the highest number of respondents being in the age range of 26 - 35 years followed by the age range of 36 - 45 years and then 46 - 55 years with only $1 \%$ coming from the 18 - 25 year of age range. Preference for laptops gave a slightly different response with the age range of 36 - 45 recording the highest of $14 \%$ followed by the range of 26 35 years and then by 46 - 55 years and lastly the age range of 18 - 25 years. Desktop on the other hand, one would say is old fashioned and commended the age range of 45 - 55 years very well although, it was as a result of the fact that their duties mostly required them to be in the office or stationed at one place to execute. The next was the age range of 36 - 45 years with the age range of $26-35$ years and 18 - 25 not opting for desktop computers and having a respective score of $0 \%$.

\section{Conclusion}

To conclude on this study, the response from the study indicated that emails and What's App makes AIDS employees to be more efficient and productive compared to other forms based on the established factors stated earlier. We can however make some conclusive deductions that, respondents within the age range 26 - 45 years are more familiar with emails and What's App than the other forms or mediums of communication including face to face, printed memos and letters as well as the notice board. Another deduction is that personnel within the age range of 46 - 55 years preferred the traditional way of handing down information which is the face to face rather than the other media of communication. Lastly, employee in the age range of 26 - 45 years prefers mobile phones, ipads, tablets, and laptops compared to the desktop. The highly rated and preferred media of communication (thus email and What's App) based on the study are the most used media utilized by Sewerage Systems Ghana Ltd. Employing the most preferred medium for communication in the organization is evidenced in the high performance of the staff which is reflective in the overall performance of the plant operations. The application of the CMC and the utilization of the 
appropriate media in the management of faecal sludge highly aided the productivity and efficiency of personnel as well the overall performance of the plant operations and hence the organization. It is believed that the involvement of $\mathrm{CMC}$ in the areas of customer service would also enhance the actual business understanding. By this assertion, it would require a common What's App platform which would involve the stakeholders and the organization for better stakeholder engagement. Again, it would also require the use of Global Positioning Systems (GPS) in the tracking of customers who brings faecal sludge into the treatment plant for processing.

\section{Acknowledgements}

The authors would like to extend their profound gratitude to the Board, management and the entire staff of Sewerage Systems Ghana Ltd., the executive chairman (EC) of the Jospong group of companies (JGC).

\section{Conflicts of Interest}

The authors would like to declare that, we have no significant competing financial, professional or personal interests that might have influenced the performance or presentation of the work described in this manuscript.

\section{References}

[1] Lawlor, B. (2007) The Age of Globalization: Impact of Information Technology on Globalization on Business Strategies. The Honors Program Senior Capstone Project.

[2] Green, L. (2002) Communication, Technology and Society. Sage Publication Ltd., London.

[3] Rogers, E.M. (1986) Communication Technology: The New Media in Society. The Free Press, New York.

[4] Rogers, E.M. (2003) Diffusion of Innovations. 5th Edition, The Free Press, New York.

[5] Kiesler, S., Siegel, J. and McGuire, T.W. (1984) Social Psychological Aspects of Computer-Mediated Communication. American Psychologist, 39, 1123-1134. https://doi.org/10.1037/0003-066X.39.10.1123

[6] Waldvogel, J. (2001) Email and Workplace Communication: A Literature Review: Language in the Workplace Occasional Papers Number 3. Victoria University of Wellington, New Zealand.

[7] Williams, E. (1999) E-Mail and the Effect of Future Developments. First Monday, 4. https://doi.org/10.5210/fm.v4i8.686

[8] Rice, R.E. and Blair, T.H. (1984) New Organizational Media and Productivity Beverly Hills. Sage, Thousand Oaks, CA.

[9] Kenrick, B. and Prahalad, S. (2014) The Impact of Computer Mediated Communication (CMC) on Productivity and Efficiency in Organization. Advances in Journalism and Communication, 2, 45-51. https://doi.org/10.4236/ajc.2014.22005

[10] Trevino, L.K. and Webster, J. (1992) Electronic Mail and Voice Mail Evaluation and Impacts. Communication Research, 19, 539-573.

[11] Ahmed, I., Ofori-Amanfo, D., Awuah, E. and Cobbold, F. (2018) Performance As- 
sessment of the Rehabilitated Mudor Sewage Treatment Plant at James Town Accra-Ghana. Journal of Water Resource and Protection, 10, 725-739.

https://doi.org/10.4236/jwarp.2018.108041

[12] Yeboah, J.S., Ahmed, I., Ofori-Amanfo, D., Cobbold, F., Agbotui, G.T. and Awuah, E. (2018) Occupational Health and Safety Status in the Management of Faecal Sludge in Ghana: A Case Study of the Lavender Hill Faecal Treatment Plant. Journal of Health and Environmental Research, 4, 42-50.

[13] Ahmed, I., Quarshie, A.M., Ofori-Amanfo, D., Cobbold, F., Amofa-Sarkodie, E.S. and Awuah, E. (2018) Assessment of Foreign Material Load in the Management of Faecal Sludge in the Greater Accra Region of Ghana. International Journal of Energy and Environmental Science, 3, 27-36.

[14] Ofori-Amanfo, D., Rockson, G.N.K., Arthur, A. and Ahmed, I. (2018) Formulated Faecal Sludge and Compost Fertilizer Pellet for Crop Production: The Case Study of the Lavender Hill Faecal Treatment Plant. American Journal of Environmental Protection, 7, 7-13.

[15] Ofori-Amanfo, D., Rockson, G.N.K., Arthur, A. and Ahmed, I. (2018) Processing Dewatered Faecal Sludge into Un Pelletized Fertilizer for Crop Production in Greater Accra-Ghana. International Journal of Environmental Monitoring and Analysis, 6, 18-25. 